\title{
CUATRO ACTITUDES MASCULINAS ANTE LA ESCRITURA DE LAS MEXICANAS EN EL SIGLO XIX: USURPADORES, PRECEPTORES, SEDUCTORES Y AMIGOS-FAMILIARES
}

FOUR MALE ATTITUDES BEFORE THE WRITING OF MEXICAN GIRLS IN THE NINETEENTH CENTURY: USURPERS, PRECEPTORS, SEDUCERS AND FRIENDSRELATIVES

\section{Resumen:}

Enel siglo XIX se libera la voz poética femenina en Iberoamérica. Las mujeres transitan desde la escritura privada a la pública. Las poetisas del segundo romanticismo mexicano aparecen en las tertulias y en los debates sociales y políticos. La reacción masculina, patriarcal, al proceso de liberación de la escritura de mujeres, encuentra suplantadores, preceptores, seductores y amigos-parientes de las escritoras, que son predecesoras de las literatas del XX, tiempo predecesoras de las literats

\section{Palabras claves:}

Literatura mexicana, estudios de género, escritoras, teoría de la recepción, patriarcado.

\section{De las escritoras invisibles PARA LA Historia}

Haciéndole cargo de que si no fuera adicta a los insurgentes no hubiera escrito a su primo Manuel hasta nueve cartas,

que es lo menos según claramente se colige de sus esquemas....

(Del Palacio, 2010a:122)

Para investigar la participación de las mujeres en el desarrollo de la humanidad, en la historia o la literatura, es necesaria la óptica de género; la mirada que descubre la presencia femenina y sus características y rasgos particulares: lo femenino y lo feminista. A simple vista, ni las mujeres ni lo femenino aparecen en los registros del pasado. Si buscamos mujeres en la historia, están ausentes o hicieron muy poco, siempre a favor de los hombres; en la ciencia tampoco aparecen; la historia de la filosofía de los hombres. La dominación masculina, como la llama Pierre Bordieau, marca que los hombres sean el paradigma de la humanidad. Los estudios de género llaman a esta ceguera, "la invisibilidad de las mujeres en la Historia" (Hierro, 1998: 29). Apenas en el siglo pasado, y gracias a las luchas de las mujeres por alcanzar la ciudadanía mediante el voto, la libertad política, favoreció el reconocimiento de las contribuciones a la vida, al desarrollo y a la evolución de la humanidad. En México, las mujeres logramos el reconocimiento de la ciudadanía, del "ser humanos-persona" (Hierro, 1998: 30), en 1953, luego de más de 150 años de exigirlo:

La batalla de la mujer mexicana por la igualdad jurídica y social, o sea e reconocimiento a sus derechos económicos, políticos y sociales, segun consigna la historia, se da a fines del siglo XVII, durante la Colonia... (En) 1778 los cigarreros de la Cuidad de México, en su mayoría mujeres, abandonaron sus labores y en tumultuaria manifestación se dirigieron al Palacio para protestar ante el virrey por el aumento a la jornada de trabajo sin el correspondiente aumento y salario. Ante la simpatía popular que se sumó a la manifestación al paso por la sallo. Ante la sinínatía popu la que se suno a la manifestacion al paso por las calles y la energia de prota disposición de las empresas... (Zendejas, 2003: 401)

Debido a que la visión y los intereses masculinos han conformado los registros históricos, las mujeres son consideradas apéndices, accesorios, comparsas de los varones; y sus acciones infravaloradas, desvanecidas, ignoradas incluso hoy día. Para algunos, los desafíos y las adversidades que enfrentó, por ejemplo, doña Josefa Ortiz de Domínguez para apoyar la emancipación que encabezó el Cura Hidalgo, se explican por el amor a Allende, más que por sus afanes de libertad: “... cabe suponer que ella cumplió con su inolvidable papel en esta historia, no tanto por la preocupación de que la independencia se retrasara, sino por el temor justificado de que fuera hecho prisionero el hombre al que ocultamente amaba (Villalpando, 2002: 17)". La Historia llama "La Corregidora" a doña Josefa por estar casada con el corregidor de Querétaro,

1 Palabras en el juicio inquisitorial contra Leona Vicario 
fenómeno de las identidades sociales asignadas que se identifica como "la mujer para otros", lo que se explica dentro la categoría de madre-esposas, en la teoría de los cautiverios de las mujeres (Lagarde, 1993: 35). Nada más alejado de la realidad histórica que el móvil de apoyar al amante. Josefa era de familia morisca, más bien mulata ella, pertenecía a una casta que sufría vejaciones sin fin por parte de los peninsulares. Rebelde, insumisa, mujer fuerte, antes del taconazo aquel que la hizo pasar a la historia como frívola "revoltosa" (Orozco, 1987: 47), Josefa ya había dado muestras del gran carácter. Cuando la invasión napoleónica de 1808, “ella ayudó a su marido a redactar la iniciativa para que en México se estableciera un gobierno con base en cortes o juntas de las municipalidades del reino (Del Palacio, 2010b: 49). En México -como en Francia en 1789 o en España, en 1808- las mujeres que participaron en las guerras de independencia de 1810 y los años siguientes, lucharon (fuera con la pluma o con la espada o con recursos propios), con la firme convicción de que debían alcanzar derechos y libertades.

Para acercarme a las cuatro actitudes masculinas ante la escritura de mujeres, hablemos de los seductores, los que suponen que el móvil de la existencia femenina es el amor a los hombres. Quienes ejercen la seducción gustan de inducir o persuadir a otras para que modifiquen pensamiento o comportamiento y se ajusten a los fines que convengan al seductor. La historia quiere hacernos creer que, por ejemplo, las mujeres de la independencia seguían a sus hombres sin que verdaderamente les interesara la causa. Devalúan el papel central de Leona Vicario al decir equívocamente, taimadamente que:

... se ha inmortalizado por todas esas leyendas tejidas a su alrededor, ciertas seguramente, que hablan de la entrega patriótica por la libertad. Cabe preguntarse si su desprendimiento en favor de la causa de la independencia tuvo como motivo principal apoyar al movimiento por sus convicciones políticas o más bien porque en él participaba el hombre que amaba... (Villalpando, 2002: 19)².

Leona Vicario, antes que Quintana Roo, se mostró apasionada de la libertad de su patria; y sus ideas ilustradas la llevaron a iniciativas propias. Más que convertirse en "correo" de los insurgentes por el amor de Quintana Roo, ella era vocera y defensora letrada de la causa libertaria desde antes. Fue en realidad una precursora de la emancipación de las clases oprimidas: ilustrada, culta, sensible, además de rica y hermosa fue emprendedora y hábil comerciante. Prueba de ello es su hábil defensa ante el reciente gobierno mexicano, que le valió recuperar parte de sus bienes -su herencia- que las autoridades realistas le incautaron en represalia de su decisivo apoyo a la causa que triunfó. Nada más lejos del temple de esta mujer que pensar en ella

2 Cabe notar la contradicción en la frase "leyendas...ciertas". El historiador padece Genderblindness" así se llama en inglés la carencia de disposición intelectual para considerar a las mujeres como personas libres, de acciones y acciones propias. como la descocada aventurera, la "revoltosa" (Balestra 63), que dio luz en una cueva por seguir a su esposo. Era mujer de carácter y con intereses propios. En su época y por jueces implacables fue categorizada como "adicta a la Independencia", así consta en el interrogatorio del Santo Oficio a Leona Vicario, abril 22 de 1813, encarcelada en el Convento de San Miguel de Belén, según descubrió la gran historiadora de la prensa Celia del Palacio en Leona, novela histórica (122). Otra investigadora nos la muestra muy lejana a una "revoltosa". En efecto, al trazar la historia de las letras femenina en el periodismo, escribe “Leona Vicario (1787-1842) heroína y considerada la primera mujer periodista, o en su defecto, la precursora del periodismo hecho por mujeres" (Hernández López, 2010: 23). ¿Por qué pensar en que fue la única? ¿Por qué negar las causas de las mujeres como obra de seres pensantes, personas activas con iniciativas valiosas en bien de toda la sociedad?

La invisibilidad se extiende al trabajo, a la salud, a la cultura, al lenguaje cotidiano y a la literatura. La utilidad de los estudios de género ha derivado en la perspectiva de género, hoy por hoy una política pública que requiere significados culturales y no únicamente significantes. Mi investigación "Historia documental de las mujeres"3 me llevó a descubrir que los libros de texto de uso corriente, los manuales de literatura mexicana escritos por mujeres en el siglo XX, (Álvarez, Millán) sólo incluían a dos escritoras como predecesoras de las narradoras y poetas que, a partir de 1930, publicaban por docenas y más. En efecto, según esos registros femeninos, sólo Sor Juana en el siglo XVII y María Enriqueta en el XIX, habían escrito en México. Además de la brecha histórica entre siglos, me inquietaba el salto entre 1650 y 1872. Mientras que en los albores de la Ilustración, desde el 1700, aquí y allá publicaban las mujeres en otros sitios, ¿cómo explicar esa escritura femenina mexicana sin antecedentes? ¿Sería cierto que no hubo pioneras, antecesoras?

¿Eran o no sus sucesoras las escritoras nacidas en la $2^{\underline{a}}$ o $3^{\underline{a}}$ década del XX, las bien conocidas y leídas incluso hoy día, como Pita Amor, Guadalupe Dueñas, Elena Garro, Rosario Castellanos, Amparo Dávila o Inés Arredondo, que son la media docena de escritoras que forman las Seis niñas ahogadas en una gota de agua (Espejo, 2009: 8); o bien las 7 escritoras mexicanas de su puño y letra, nacidas en las $4^{\underline{a}}, 5^{\underline{a}}$ y $6^{\underline{a}}$ décadas, también escritoras consagradas, de talla internacional como Brianda Domecq, Beatriz Espejo María Luisa Puga, María Luisa Mendoza, Ethel Krauze, Aline Petterson y Angelina Muñiz-Huberman, las Mujeres que cuentan (su autobiografía) (Domecq, 1998: 209)? ¿No podía escribirse una historia de las letras femeninas en el siglo XIX?

3 Proyecto registrado en el Consejo Divisional de Ciencias Sociales y Humanidades de la Universidad Autónoma Metropolitana, Ciudad de México, \# 282, cuyos resultados han recibido dos Menciones Honoríficas. 
Los estudios de género, la teoría de la recepción y mi lectura de periódicos viejos y el conocimiento de otras literaturas, me impidieron aceptar esos saltos, esas brechas, esa invisibilidad. Escritoras como Angeles Mastretta, Elena Poniatowska, Rosa Nissan, leídas en el exterior, traducidas a varias lenguas, deberían tener antecedentes, provenir de un linaje, haber leído a otras mexicanas, a sus madres y abuelas, incluso bisabuelas literarias. Ciertamente, hubo escritoras en el XIX, caldo de cultivo en el proceso de profesionalización literaria en mi país.

Un recorrido por bibliotecas, hemerotecas y librerías de viejo, además de la revisión de periódicos y revistas literarias del XIX, me ayudó a recuperar un centenar de poetisas amén de una veintena de libros de versos editados en el siglo XIX. Al principio, no fue fácil encontrar las fuentes, como era de suponer, pues ni bibliógrafos ni bibliófilos -muy pocas bibliófilas- veían la escritura femenina. Lectora de grandes periódicos como El Renacimiento, El Imparcial y El Federalista, yo sabía que ahí publicaban mujeres. A cuentagotas si se quiere, pero en todas las publicaciones periódicas había encontrado plumas femeninas, voces femeninas, seudónimos femeninos. Además, en Europa, en Latinoamérica, tras las Revolución Francesa y los movimientos de independencia de América Latina, las mujeres participaban en las tertulias y organizaban asociaciones poéticas, junto a las Brontë, a Jane Austen, ahí estaban Carolina Coronado, Clorinda Matto, Nisia Floresta. Además de acudir a los grandes proyectos culturales, me desplacé hacia lo que la teoría de la recepción llama, los lectores profesionales, los editores. Advertí que luego de la Independencia, todos buscaban lectoras y publicaban para las mujeres, luego, en la época de Benito Juárez, muchos editores publicaban mujeres. Para el Porfiriato, ya las mexicanas estaban listas para publicarse ellas mismas, escribir y tener sus propias empresas culturales. Las románticas mexicanas no estaban en las historias literarias escritas en el XX, por la consabida invisibilidad de las mujeres en la historia. Algunos diarios decimonónicos no favorecían la difusión de la poesía femenina. Sin embargo, la mayoría de publicaciones ocasionales o marginales, diarios conservadores -católicos- o lecturas de entretenimiento, como solían llamarse, publicaban mujeres.

En casi todas las publicaciones existe rastro de que, aun cuando ni la poesía femenina ni las poetisas fueran visibles para la lectura oficial o la canonizada, críticos y escritores hablaban de ellas, escribían sobre ellas, las describían e incluso las imitaban, como en $E$ Liceo Mexicano o la Revista Nacional de Letras y Ciencias. Con este dato recordé la práctica androcéntrica que la crítica literaria feminista reconoce como “la representación de lo femenino realizada por lo masculino" (Showalter, 694). Recuperar la poesía escrita por mujeres en el periodo comprendido entre la Independencia y la Revolución, implica reconocer la recurrencia y alternancia en los juegos de imágenes y espejos, propios de varones o usurpados a las mujeres. Implica enterarse de la exégesis y la hermenéutica, los metalenguajes y manifiestos literarios que los escritores varones expresaron frente al signo lingüístico "poetisa" y a la práctica literaria de los referentes reales y textuales de tal signo.

Durante la investigación se hallaron cuando menos cuatro actitudes de los escritores mexicanos ante la escritura de mujeres. De ellas, tres contribuyen a la invisibilidad de las mujeres en la historia literaria, en la cultura y en las ideas de nuestra sociedad. Excede esta investigación conocer si sólo se dan en el siglo XIX:

Usurpadores: hombres escriben como si fueran mujeres, y recurren a seudónimos y ocupan espacios de mujeres. Ejemplo, Vicente Riva Palacio, suplantador de poetisas con el personaje de Rosa Espino (Schneider).

Preceptores: instructores y maestros que canonizan sobre el arte poético de las mujeres. Ejemplo, Ignacio Manuel Altamirano, el Maestro de América, cuya "Carta a una poetisa" es un manifiesto literario y marca el deber ser de las escritoras.

Seductores: hombres de letras, políticos culturales que fingen no ver la escritura femenina, aunque en realidad desean apoderarse de ella. Ejemplo, Justo Sierra, que argumenta que las mujeres no sabían ni podían escribir, y que se casó con una reconocida sonetista.

Amigos-parientes: varones admiradores de las poetisas, y cuya amistad les vale a ellas ser incluidas en sus proyectos literarios y respetada su creatividad y sus ideas (Granillo, 2010).

Un centenar de mujeres cultivaron la poesía, luego la narrativa y el ensayo en el siglo XIX, en la ciudad de México y en la provincia. Muchas de ellas lograron mantenerse con la pluma y más de una veintena publicaron fuera de México, en el resto de América y aún en Europa; unas 6 fueron traducidas a otras lenguas (Granillo, 2012). Con la perspectiva de género y la revisión de las prácticas lectoras que recomienda la teoría de la recepción, se pueden recuperar esas herencias valiosas que la ceguera de género no logra ver. Recuperar la escritura pública de las mujeres dotara a las literaturas nacionales de todo su esplendor.

\section{Usurpadores}

Dedicada al difícil estudio de la poesía desde hace algún tiempo, no me había atrevido a publicar mis humildes producciones por temor de que no fueran dignas de la ilustración pública, más hoy me decido a hacerlo, aunque con temor, porque así me lo ruegan personas a quienes por gratitud estoy obligada... (Schneider, 1993: 140$)^{4}$

4 Supuestas palabras de Rosa Espino, fenómeno de travestismo literario, seudónimo poético de Vicente Riva Palacio, cit por Luis Mario Schneider, 1993, p. 140. 
Horizonte histórico de por medio, cabe reconocer la usurpación en el travestismo literario, fenómeno masculino de discurrir sobre lo femenino. En una plaza pública equitativa, respetuosa de las diferencias, los hombres discurrirían acerca de lo masculino y las mujeres acerca de lo femenino. Mejor aún, los seres humanos de cualquier sexo serían capaces culturalmente de discurrir acerca de los dos o más géneros. Este ideal del tercer milenio era impensable para la mayoría de los varones en el siglo XIX. La construcción masculina de la identidad nacional llamada "Bello Sexo" así lo confirma. La abundancia de la usurpación masculina del discurso femenino en forma del travestismo literario, conforma una tendencia cultural digna de ser más ampliamente estudiada

El más famoso travestismo literario es el de Rosa Espino, una desconocida que de buenas a primeras comenzó a publicar poesías, en diciembre de 1872, en la sección "Variedades" del célebre periódico. Rosa había enviado dos apólogos, "La luz y las Flores" y "El perfume y la Oración", con carta al diario El Imparcial. La recepción del público lector fue enorme. Rosa Espino, poetisa de Guadalajara, con sólo 16 años de edad, adquirió fama y sonado éxito y tras un homenaje nacional aun fue admitida en el Templo de las Letras, el Liceo Hidalgo, junto a grades escritoras como Rosa Carreto o Laureana Wright de Kleinhans. El impacto de Rosa fue favorecido por una campaña publicitaria. Simultáneamente al homenaje, periódicos capitalinos, como La Reconstrucción, se apresuraron a publicar de nuevo los apólogos, y para febrero siguiente, las obras de la "espiritual poetisa jalisciense" aparecían también en $L a$ Reconstrucción, El Correo del Comercio y El Amigo de la Verdad, de Puebla, otros más de provincia. Publicaban sus poemas, y además, El Imparcial mostraba especial empeño en divulgar toda noticia acerca de la niña. A diferencia de otras escritoras, la inserción de su obra iba siempre precedida por noticias como estas: "Algunos periódicos se han dignado en reproducir el apólogo, intitulado: 'La Luz y las Flores', que la simpática señorita Rosa Espino nos remitió desde Guadalajara". O bien "Rosa Espino aparece hoy en El Imparcial honrado con una guirnalda de Madreselvas...". Rosa Espino fue reconocida vertiginosamente por lectores y críticos como "la espiritual poetisa jalisciense", y la farsa, desparecido El Imparcial, fue continuada por El Federalista, e incluso El Búcaro, suplemento literario del Correo del Comercio. Tocó al Federalista, en abril de 1875, anunciar la publicación del primer -y único- tomo de poesías reunidas de Rosa, Flores del Alma, hoy inaccesible, seguramente perdido. El editor había sido Francisco Sosa, la imprenta, del señor Ponce de León.

De la impostura de Rosita habló Juan de Dios Peza. Tres años después de la edición del libro, encuentra ocasión de referirse a la farsa, pero sin develar el misterio, en sus Poetas y escritores modernos mexicanos, de 1878, se sintió obligado a incluirla. La impostura duró 13 años y aún más, perdura en este siglo y rebasó las fronteras nacionales llegando hasta España en este siglo. Será difícil saber quiénes, conociendo la verdadera identidad, se esforzaban por ocultarla, y quiénes inocentemente creían en la niña prodigio de Jalisco, que era, en realidad el General Vicente Riva Palacio. Sus poemas gustaban mucho, como que provenían del genio masculino y se ajustaban al concepto de mujer ideal. Veamos la transmisión, por ejemplo, de "Un Recuerdo", originalmente publicada en El Búcaro, en noviembre de 1873. Apareció luego, en 1875, en Flores del Alma. De ahí lo tomo, La Abeja, para su edición del 14 de agosto de 1875, pues el índice señala Flores del alma, antes del poema. El Parnaso Mexicano, en 1905 lo reproduce con otros poemas de Rosa.

Aunque Rosa Carreto y Laureana Wright también eran socias del Liceo Hidalgo, no lograron atraer la atención de los historiadores de la literatura igual que Rosita. El hecho de que un hombre escribiera como mujer y que la suplantación lograra convencer a lectoras y eruditos, precipita a la crítica literaria mexicana hacia el fenómeno literario de la escritura de género. Todavía no se realiza ese estudio. Rosa Espino y Riva Palacio ofrecen discursos ad hoc para advertir los rasgos distintivos de género. No se trata ya tan sólo de géneros gramaticales, sino de la definición existencial convertida en concepto antropológico y elevado a categoría de análisis por el llamado feminismo académico:

El género puede definirse como una red de creencias, rasgos de personalidad, actitudes, sentimientos, valores, conductas y actividades que diferencian hombre de la mujer mediante un proceso de construcción social que tiene una re de de la muje

serie de aspectos distintivos. Es histórico; se presenta en el seno de diversas macro
y microesferas... (Benería y Roldan, 1992: 24).

Por la calidad de su poesía -horizonte estético, gusto de la época-, la fama de esta niña de Guadalajara cruzó el mar y llegó a España, distinción que anhelaron muchos poetas y otras tantas poetisas. Fingir la existencia de una poetisa mexicana ratifica la calidad de usurpación de este travestismo. En el último tercio del XIX, ya existían poetisas renombradas, como Isabel Prieto, Rosa Carreto y muchas otras.

El domingo 7 de enero de 1872, apareció la Edición Literaria de El Federalista, cuyo director y redactor en jefe era Alfredo Bablot. Encabezan la página legal de “Redactores", las "Señoras" Carmen Cortés, Pilar Moreno, Isabel Prieto de Landázuri, Gertrudis Tenorio Zavala y Rita Zetina Gutiérrez. Entre los “Señores” estaban Manuel Orozco y Berra, Manuel Payno, Francisco Pimentel, y también Vicente Riva Palacio y Francisco Sosa. La Edición... inaugura sus artículos de opinión con una disquisición filosófica que firma Bablot, y que se titula "Instrucción obligatoria y gratuita de la mujer":

Instruir a la mujer es hacerla cooperar al movimiento del progreso incesante de la humanidad; es elevarla, es coadyuvar a su emancipación...// Si se hiciera obligatoria 
entre nosotros la instrucción de la mujer, no habría dentro de veinte años en toda la República Mexicana un niño de ocho o diez años que no supiera leer, escribir y contar. ... Creo que en ningún país hay actualmente ley alguna que haga obligatoria la instrucción de la mujer. Esto es incomprensible en el siglo en que vivimos.// Haría honor a México el tomar la gloriosa iniciativa de esta gran mejora social que envuelve una de las cuestiones morales y políticas de más importancia para el presente y el porvenir... ( Bablot, 1872: 7-8).

El mismo Alfredo Bablot, solía también "escribir como mujer entre hombres" bajo el seudónimo de "Raquel" y de "Flora" (Ruiz Castañeda Y Márquez Acevedo, 1990: 24). El 28 de enero, se firma como "Flora", y escribe un artículo sobre la envidia y la rivalidad profesionales de Miguel Ángel que le fue inspirado a la "autora" por artículos anteriormente publicados ahí. Flora comienza su prosa "Miguel Angel, Episodios", hablando de Bablot como si fuera otra persona: "He leído con admiración... la historia de la Academia de San Carlos trazada a grandes rasgos por Alfredo Bablot...". Y termina con un discurso indudablemente feminista: “El carácter sombrío del célebre pintor y escultor, incompatible con el generoso corazón que en general poseen los artistas, se hizo, desde entonces, todavía más agitado, más misántropo y más insociable" (Bablot, 1872: 53). Es practica editorial recurrir a la estratagema de escribir las misivas que luego aparecerán en la sección "Cartas del editor". Pero, ¿cómo se explica la estrategia de cambiar de sexo? ¿Será que los varones se apropian de una identidad femenina para poder expresar lo que como hombres no les está permitido? Mientras que Bablot recurre a "Flora" o a "Raquel" para expresar lo femenino, pero sin descartar a las mujeres. Bablot imita, El General usurpa.

Explica Francoise Carner, en su estudio de "Estereotipos femeninos en el siglo XIX":

En todos los casos, la anuencia masculina es necesaria para los cambios en la vida de la mujer, de su educación o de su trabajo. Hay partidarios burgueses de la mujer asalariada que defienden su posición con diversos argumentos... También existen los que piensan que con una preparación adecuada las mujeres pueden desempeñar cualquier tipo de trabajo, pero en la práctica son refutados por los hombres que temen encontrar en las mujeres competidoras desleales (Carmer 1987:107).

Incluso en el caso de que el travestismo literario fuera una ironía de lo masculino ante lo femenino, o una forma sutil de literatura prescriptiva acerca de la esencia y la conducta de las mexicanas, el análisis detallado ha de contribuir al conocimiento de las relaciones de poder entre la literatura femenina y la masculina. Si la creatividad femenina existía, el poder de publicar no estaba pues al alcance de todas las escritoras. Había una selección, una discriminación, una censura. Selección, discriminación y censura que explicaría la desaparición de las poetisas en la historia -que no en la práctica ni en la vida- literaria del siglo XX.

\section{Preceptores}

¿Quiere usted cantar como mujer? Es preciso poseer

el ardiente corazón de Safo, o la imaginación exaltada

de santa Teresa. ¿Quiere Usted cantar como hombre?..

Ignacio Manuel Altamirano, Carta a una poetisa ${ }^{5}$.

En la literatura mexicana, el caso de Sor Juana Inés de la Cruz y la Carta a Sor Filotea de la Cruz, documenta la tradición masculina de prescribir a las mujeres, de adoctrinarlas y enseñarles el "deber ser femenino" específicamente a las escritoras. El artículo "Poetas y poetisas o Ellos y Ellas" que Niceto de Zamaçois, autor español avecindado en México, publicó en 1852 en El ensayo literario, publicación de Jalisco, que inauguraría, para el Romanticismo, la tradición de "Maestros de las poetisas". Admirador de las poetisas, más que censor, Zamaçois incluye en su crítica sobre las prácticas poéticas que a diestra y siniestra se realizan deplorablemente, tanto a los hombres como a las mujeres de entonces. Así que da noticias de las escritoras, las revela y aun las pone de ejemplo a seguir para ellos:

...Muy dignas de elogio son las jóvenes que se dedican al estudio de las bellas letras. Porque dotada generalmente la mujer de sensibilidad, de virtud y de imaginación viva, puede hacer muchos bienes a la sociedad, porque el hombre siempre está dispuesto a seguir las máximas de ese sexo encantador. Pero para esto es preciso, como antes dije, que estén dotadas de instrucción y de talento; de lo contrario sólo serán unas marisabidillas insoportables.

... Y entre las poetisas modernas tenemos, en España, a la Avellaneda y a la Coronado, brillando como dos astros, gracias a su instrucción y talento, y rivalizando con los mejores poetas de nuestra época. Mención no menos honorífica merecen las poetisas que hoy se dejan ver en varios puntos de la República, honrando la literatura del país donde nacieron. ¡Guadalajara!, ese suelo encantador, cubierto por un cielo siempre limpio; ese país hospitalario y religioso, cuya grata memoria ni el tiempo ni la distancia borrarán de mi corazon; ese país donde tan buenos y verdaderos amigos he dejado, cuenta en su seno apreciables e instruidas jóvenes como la señorita Ignacita Cañedo, doña Josefa Sierra y doña Isabel A. Prieto, bajo cuyas composiciones no titubearian en poner su nombre Nicomedes Pastor Diaz y Bretón de los Herreros. (Zamacois, 1852: 212)

Emilio Rey, hacia la mitad del siglo 1852, alienta entusiasmado en una Oda, “ A las poetisas de Jalisco" a seguir escribiendo:

...En santo arrobamiento

¡Lindas cantoras de Jalisco bella

5 Recomendaciones del "Presidente de la República de las Letras", el maestro Ignacio Manue Altamirano, en su célebre "Carta a una poetisa", preceptiva literaria del XIX; cit, por Rojas Otalora 1996, 225. 
Con tintes de ternura y sentimiento

Pintad de la virtud la blanca estrella

Del santo amor de madre

Con dulcísimo acento

Cantad los blandos, celestiales goces;

$\mathrm{Y}$ pintad ese afecto peregrino

Que con sagrados nudos

Une dos corazones delicados

De perfidia desnudos,

Como se unen dos flores

De vuestras fibras rotas.

Francisco Zarco eleva a la mujer amada a la dignidad del amado. Reconoce que al poeta "sólo una mujer con alma de poeta puede amarlo". Para 1860, José María Vigil e Ireneo Paz exclaman arrobados ante el genio de Isabel Prieto, "Canta pues, tierna amiga, canta" y "Sigue cantando; pues tu voz impera...". Hay más evidencias del cortejo y la admiración que sigue a la aparición de las poetisas, del amor -a veces retórico y otras no- que despertaban las mujeres cuando escribían entre ciertos hombres. Ante Josefina Pérez, Vigil exclama "Recibe, pues, Oh Niña, este homenaje"; y Luis Calderón la consagra como "Violeta tú de un nuevo paraíso". Lorenzo Elizaga y Luis G. Ortiz también la exaltan. (Granillo).

Pero Ignacio Manuel Altamirano, "el presidente de la República de las Letras" sostiene otro tono en la "Carta..." a su poetisa. Publicada en varias parte en 1872, en la segunda época de El Domingo, Semanario político y literario, el Maestro refuerza en ella la intención, manifiesta en otros textos de crítica literaria, de impulsar una literatura propia, con temas y motivos mexicanos, paisajes y personajes del terruño. Con fina ironía, critica los usos y abusos de la anónima poetisa: excesiva religiosidad que raya en lo ridículo; importación de caracteres y situaciones europeas -mayormente caballeresca- que en nada representan lo nacional. Altamirano le pregunta a su joven interlocutora:

¿Cómo traer a México los castillos feudales que se elevan en las rocas y se pierden en las nieblas; cómo evocar los recuerdos de hazañas que no se conocen, porque apenas se conoce su historia; cómo vestir a un "caporal" la armadura de acero bruñido, y dar a un indio vendedor de guajolotes el aspecto de un escudero? (Rojas, 1996: 226).

Para los fines de esta investigación, esta pregunta es capital: ¿quién es la poetisa, la destinataria del discurso ad baculum? La crítica ha considerado que estos consejos del Patriarca Altamirano son extensivos a muchos escritores, en especial los jóvenes que entonces adolecían de los señalados vicios extranjerizantes. Dice el Maestro: "cada país tiene su poesía especial, y esta poesía refleja el color local, las costumbres que le son propios".
Algunos consideran que la poetisa pudiera ser una ficción, un personaje retórico que según tal crítica, no existe ni existió más que en la mente del forjador de la literatura nacional. Así, la destinataria es una "mujer inventada", semejante a la de los filosofemas del emblemático periódico literario de la República Restaurada, El Renacimiento (Batiz, 1993). Si se acepta sin más que haya sido inexistente, tendríamos que admitir que esta ficción por ser mujer y escritora constituyó el pretexto para adoctrinar a todos y a todas. Pero especialmente a ellas, a quienes el Maestro se siente obligado a reconvenir. La interpretación tradicional incomoda las responsabilidades de la crítica literaria feminista $y$, a decir verdad de la crítica literaria. Hace falta examinar de cerca la producción de poetas y poetisas a contra luz de la "Carta...". El examen revelará mucho acerca de la evolución de la poesía en México. ¿Quiénes -ellos y ellas-, cuándo y dónde escriben lo que Altamirano juzga?

Sin duda, admitir la inexistencia de la poetisa supone avalar la idea patriarcal de que las mujeres no tenían nada que decir ni mucho menos que escribir. Un poco de imaginación y la técnica de extrapolación permiten ver que detrás de la tesis de la inexistencia de la poetisa, están la ignorancia de las poetisas de carne y hueso y el prejuicio cultural contra las escritoras del XIX. Y, me atrevería a decir, el desconocimiento de las tendencias y los temas poéticos de la época. Los jóvenes escritores recibirían y leerían el mensaje, pero al estar dirigido a una poetisa, ninguno de ellos se sentiría herido por la mordacidad de la crítica; pues la poetisa, en tanto que mujer, sería la nada para ciertas mentalidades masculinas. Puede citarse a la feminista estadounidense que dice "la mujer - para estas mentalidades- no tiene nada que decir; no existe en el mundo discursivo masculino" (Showalter, 1991, 694). En contraste, afirma el editor contemporáneo que:

... parece entenderse este texto ("Carta...") como una sutil reconvención a los jóvenes artistas que se dejaban llevar por temáticas elaboradas hasta el cansancio y que se consideraban a menudo como propias de la producción literaria del sexo femenino (Rojas, 1996: 222).

Algo me queda muy claro, que el fenómeno que he llamado "escribir como mujer entre hombres", ha quedado plasmado en la "Carta..." de Altamirano, en preguntas retóricas que él mismo, caballerosamente, contesta: “QQuiere Usted cantar como mujer?... ¿Quiere Usted cantar como hombre?...". Y significativamente concluye con la negación de toda posibilidad poética o intelectual con identidad femenina: “QQuiere usted filosofar? Entonces deje usted a las mujeres y lea en el libro del mundo...". Y ello a pesar de que la propia cultura del siglo XIX obligaba a la belleza y la debilidad del sexo femenino. Se trata de una "vuelta de tuerca" sobre la noción masculina, muy mexicana, de que las escritoras debían "olvidarse de la debilidad". Persiste actualmente la tendencia cultural de que los escritores se conviertan en maestros de las escritoras. En 
una conferencia internacional acerca de los problemas de las mujeres para expresarse entre los hombres ${ }^{6}$, Elena Poniatowska señaló recientemente a Enrique Castillo Pesado como "Maestro de las mujeres periodistas". La también escritora Alejandra Lajous se lamentaba de la asfixia en los medios de comunicación masiva y de los manuales de estilo preparados por los hombres. "Cuando los periodistas quieren elogiarla a una, sólo se les ocurre decirte “Escribe Usted como todo un hombre!”' (Llamas, 1997). Cualquier mujer genuina recibiría con suma desconfianza este "elogio".

\section{Seductores}

Sería interesante ahondar en la personalidad del seductor

y estudiar por qué en el siglo XIX mexicano y en su literatura

no se encuentran grandes figuras de Don Juan

sino pequeños seductores sin categoría.

sino pequeños seducto

En 1868, la primera de las célebres "Conversaciones del domingo" de Justo Sierra concede claramente un espacio y un destino especial a las mexicanas. Al hablar de "el Parnaso mexicano", y luego de ponderar la influencia de la guerra sobre la creación literaria nacional -alusión directa a sus antecedentes de República Restaurada-, declara: “Un elemento hay, sin embargo, de vital necesidad para la literatura de todos los países, y que, digámoslo sin embozo, no se hace sentir entre nosotros. Dejadme llamarlo el cariño de la mujer. La mujer forma, en la historia de la civilización, la faz del sentimiento y de la poesía" (Sierra, 1997: 72).

Sierra dirigió la mayoría de tales "Conversaciones" a las mujeres, a quienes interpelaba llamándolas "niñas", "queridas lectoras" o "lectoras mías". De hecho, toda la creación de Don Justo, revela la intención firme y concentrada, en prosa o en poesía, de escribir acerca de y para las mexicanas. La mujer es, a la vez, protagonista e interlocutora de Piedad, Cuentos Románticos, Marina, Playera. Sierra se ocupó de la educación femenina y de la feminidad tanto en su Disertación sobre el Matrimonio, "el más antiguo de sus trabajos en prosa" (Sierra, 1977: 37), como en sus versos jocoserios “¿Quién las entiende?" (1871). Y por numerosos poemitas poblados de ensoñaciones marinas, de hadas y amadas de ultratumba, pululan Cármenes, Lauras y otras Señoritas. Más aún, las mujeres constituyeron una preocupación constante, vital, en todo proyecto gubernamental en el que Sierra participara. Así, de palabra y de obra, favoreció innumerables escuelas para mujeres, jardines de niñas o aulas de artes y oficios. Como muchos otros en el Siglo XIX, el autor mostró un interés reiterado en la mujer, tópico romántico que en él, a medio camino entre el romanticismo y el modernismo, adquiere rasgos obsesivos. Por la lectura de El ángel del porvenir (1869),

6 Women in the Media, Facingobtscales... Changing, Mujeres en los medios, 7 y 8 de marzo de 1997 Hotel Camino Real, Ciudad de México. Convocatoria internacional de International Women's Media Foundation, anfitriona nacional María Victoria Llamas. su novela inconclusa es una piedra de toque, la "tesis" de esta novela folletinesca y llena de digresiones, propone que las mujeres serán las salvadoras de México. Percibe así el deterioro moral de la vida:

Nuestra época está enferma de la espina dorsal. Se ha encenagado en los placeres, y no morirá, porque los pueblos nunca mueren; pero necesita rejuvenecerse. La raza latina ha caído ya dos veces, las dos el cristianismo la ha levantado; tendrá aún su tercera caída y el cristianismo la levantará. El imperio fundado por César cayó bajo la lanza de los tártaros; las bombardas de Mahomet derrumbaron el imperio de Constantino. ¿quién echará abajo el imperio fundado por Bonaparte? ¿Y sabéis cómo se llama el imperio del vencedor de Austerlitz? Se llama la civilización latina. La salvación vendrá del norte...En la América española no hay ningún pueblo virgen. Allí el vicio está en la sangre... (Sierra, 1977: 198-9)

Sin embargo, Sierra nunca explicó ni desarrolló las ideas en torno a "la mujer fuerte ella será el ángel del porvenir". Antes bien se perdió en una telaraña interminable de personajes e intrigas fantásticas, cambios de ambiente y de episodios, donde ningún personaje femenino se acerca al arquetipo de la mujer fuerte bíblica. Explica el editor actual:

...resultado de juvenil impulso, ... en caudalosas narraciones de intriga interminables... Sin plan alguno, el joven prosista fue escribiendo episodio tras episodio. Trataba de narrar las aventuras de los miembros de una sociedad secreta, pero apenas llegó a iniciar su desarrollo en la parte publicada, probablemente la única escrita... Como en la novela insiste en el trazo de caracteres, análogos a los esbozados en escena del drama Piedad, el folletín inconcluso, por aquello que el autor llamó "donjuanismos satánico e infantil", liga el drama con las crónicas y los cuentos (Sierra, 1977: 9).

En un ambiente de traiciones, muertes, infidelidades y lujuria; raptos y reencarnaciones, la "sociedad de los hermanos del crimen" realiza una empresa fantástica: el grupo de aristócratas se propone acabar con la institución matrimonial mediante la práctica del adulterio. Ningún personaje, ni masculino ni femenino, logra en los 22 capítulos publicados, alcanzar estatura angelical ni de salvación. Todas las mujeres son lascivas y proclives a la seducción. El narrador, más que escandalizarse, se deja llevar por los vaivenes de tal "donjuanismo". De haberla concluido, Sierra con seguridad hubiera impulsado la idea de la necesaria redención de la mujer, viciosa por naturaleza; la Eva perversa y pecadora, que incita a Adán a la maldad, tópico del modernismo.

Detrás de esta "cierta obsesión por las mujeres" están implícitas ciertas actitudes persistentes todavía entre los mexicanos y en la vida literaria nacional. Por un lado, algunos escritores las consideran bellas y dignas, pero también peligrosas y malas. Por otro, si bien aparentan incorporarlas al proyecto nacionalista para que trabajen 
en favor de la patria, pretenden ignorarlas como seres humanos cabales, y por eso desconocen, ignoran, o silencian su expresión poética. Tal vez exista otro aspecto en las relaciones entre escritores y escritoras, ese que se identifica con el "donjuanismo satánico e infantil". Y ese donjuanismo bien pudiera ser una cierta seducción, un afán de cautivar y encantar la expresión poética femenina-y a las poetisas de carne y hueso-. Seducir a las poetisas acaso haya implicado su reducción al silencio, su desaparición de la historia literaria.

La obra poética de Luz Mayora es ignorada hasta la fecha. Consta que era una poetisa por un testimonio autorizado que la inserta dentro de la tradición poética femenina mexicana diciendo:

\section{Los nombres de las Sras. Pilar Moreno, Gertrudis Tenorio Zavala y Rita Cetina Gutiérrez, son los únicos que, en este momento, acuden a mi infiel memoria; pero por ser los de tres distinguidísimas poetisas, bastan para acreditar mi dicho, y sólo por ser los de tres distinguidisimas poetisas, bastan para acreditar mi dicho, y solo
siento no poseer en mi ausencia de aquel país alguna muestra de sus bellas obras con que recrear a mis lectores (De Olavarria, 1887: 94).}

Es el único registro del caso de una esposa poetisa que no trascendió, precisamente por ser casada. Es decir, que siendo señorita, su expresividad poética alcanzó notoriedad y fama pero ya casada desapareció todo rastro de su poesía.

Su esposa (de Justo Sierra), mexicana, hija de un distinguido español, es una excelente profesora, una poetisa no bien revelada aún, una escritora de severo estilo, como severa y sólida es su vasta instrucción: es la Sra. Dra. Luz Mayora que, apenas entrada en la primavera de la vida, ha conquistado cuantiosa porción de gloria, promoviendo con inusitado impulso la reforma de la instrucción que debe darse al Bello Sexo, en que tan brillantemente figura... (De Olavarría, 1887: 95).

¿Habrá seducido Justo a Luz, es decir, la habrá hecho caer en un error o pecado -no escribir poesía- siendo ella nieta del gran poeta Manuel Carpio? ¿Fue Luz seducida para que abandonara las letras y se recluyera en las aulas? Entre las prácticas de escribir la historia literaria en México ¿existirá la tradición de seducir al testigo, en este caso a Olavarría, cuyo testimonio parece corromperse y no fructificar en el registro de la poesía de la esposa de Sierra? ¿Sería esa la reacción del enamorado, debida al encantamiento de la cautivadora, de aquella de quien se puede decir "esa mujer me ha seducido"?

Una cosa es cierta, la actitud de ignorar a las mexicanas como productoras poéticas está presente en Sierra, desde aquella primera "Conversación del domingo", cuando afirmaba acusador: "La niña mexicana no ama la literatura nacional". Este gran seductor, por lo del donjuanismo -sí consigna la existencia de poetisas nacionalesseñala, antes de la afirmación de odio femenino, que ha "habido pocas, pero brillantes poetisas". Y menciona a Dolores Guerrero, Isabel Prieto ("acento no lujoso, pero si más delicado que el de George Sand"), Isabel Pesado, Esther Tapia (comparable con Gertrudis Gómez de Avellaneda y Carolina Coronado), Susana Massón, y su paisana Gertrudis Tenorio. Y sin embargo denuncia -sin sentir la necesidad de comprobar- la ignorancia en las lectoras mexicanas: "Pero preguntad a estas jóvenes (las poetisas) si han encontrado estímulo en sus amigas. Ya nos figuramos su contestación".

Y la afirmación de Sierra es más sorprendente cuando comprobamos que sus lectoras sí leen, pues le replican y le escriben; y Justo y la niña mexicana dialogan en las Conversaciones. Y hablan, además, de la literatura mexicana, de la poesía y los poetas, de la literatura nacional que la niña sí ha leído:

El lunes pasado, caros lectores, recibí una carta anónima, que voy a tomarme la libertad de comunicaros, porque además de que va estrechamente ligada con la borrascosa historieta que os relato, me ha hecho conocer ciertos incidentes, que me hubiera sido imposible participaros sin el auxilio que en forma de carta nos ha prestado este benévolo anónimo, bajo el cual no nos ha sido muy difícil, como no lo será para muchos de vosotros, descubrir una de las más bellas elegantes, con que se engalana nuestra sociedad... (II, 148).

A la Señorita Isabel L. - Permitid, señorita, que conteste con un folletín vuestra preciosa cartita del mes pasado. En ello encuentro grande placer y utilidad, porque tan agradable correspondencia me proporciona la ocasión de repetir expresiones de afecto... (II, 168)

Descargada así mi conciencia, hablemos, amiga mía, como cuando... (II, 169).

Volvamos a vuestra carta... Vivís, Isabel, en una región que me han pintado bellísima y llena de encantos. (II, 170)

Y suponed también que escuchamos todas esas cosas divinas al lado de Luis G. Ortíz, cuya plática delicada y elegante os agradaba tanto porque tiene el sabor vivo y perfumado de esas pastillas del serrallo ${ }^{7}$, a las que comparabais sus versos.

Gozaríais mucho. Allá os envío, para que leáis en vuestros ratos de ocio algunos números de la Guirnalda, periódico veracruzano, entre cuyos redactores está Santiago Sierra, cuyas trovas os gustan tanto, y que no sólo es mi hermano por la sangre, sino por el culto de nuestra madre, por el amor a la poesía y por la religión del porvenir. (II, 171).

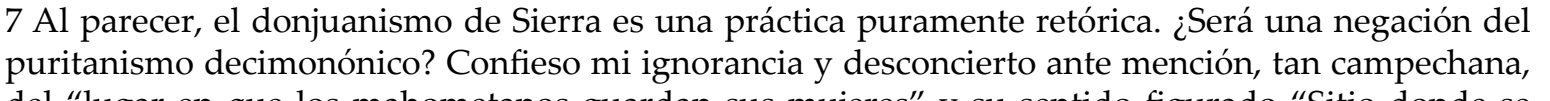
del "lugar en que los mahometanos guardan sus mujeres" y su sentido figurado "Sitio donde se cometen actos obscenos". Dicc. Larousse 1991. 
Acaso por esta tendencia a seducir para poder ignorar la expresión femenina, la historia oficial de la literatura mexicana ignora la nómina de escritoras del siglo XIX que ahora presento. Tal actitud correspondería con la denuncia velada de Marcela, la protagonista de Talladoras de montañas, mujeres (en) cintas de amor, de una narradora contemporánea, "biznieta” poética Luz y de Isabel: “... a las mujeres se nos plantea siempre un doloroso dilema: ser amadas o ser creadoras" (Espinosa, 1997: 97). Seguramente, a Luz Mayora también se le planteó ese dilema: es fácil imaginar quién decidió por ella.

\section{Amigos-parientes}

Yo he sido en este mundo tan dichosa

como hija, como madre y como esposa

cuanto se puede ser.

Isabel Prieto de Lándázuri (Vigil, 1883: 89)

Además de la exaltación romántica, el refinamiento y la instrucción ampliaron los horizontes en las relaciones de género. Para los escritores, las poetisas, mujeres cultas y educadas, de buen gusto y, por lo mismo, hermosas, ya no constituían simplemente musas, eran la encarnación del ideal romántico femenino. Como esposas, fundamentaban la esperanza de construir una familia digna, ilustrada, desarrollada -cimiento nacional- de acuerdo con la ideología del progreso. Dice Carmen Ramos Escandón que, en el siglo XIX, el estado liberal mexicano tenía necesidad "de consolidarse apoyado en la unidad social básica, la familia". Y que "la situación de la mujer... sólo tiene sentido en la familia" (Ramos, 1987: 149), modelo victoriano.

Las poetisas románticas que trascendían los límites del "sexo débil", deben haber sido mujeres inteligentes, interesantes y sumamente atractivas en el ambiente literario. Es fácil imaginar que protagonizaron muchos amores platónicos y varias pasiones tumultuosas. Está documentado cuando menos un caso de amores ilícitos: el de Laura Méndez y Manuel Acuña. En vista de la tendencia social a que los escritores se relacionaran amorosamente con escritoras, los artistas con las artistas, cabe poner en entredicho las afirmaciones de la crítica actual respecto de las mujeres como de la poesía femenina del XIX.

En general, las relaciones literarias amorosas y familiares han sido poco estudiadas, pese a que encontré antecedentes desde la poetisa del Diario de México Mariana Velázquez de León, hija de Don Joaquín Velázquez de León, y tal vez sobrina de Josefa Velázquez de León, la esposa de Ignacio Bartolache. Y era común, entonces como ahora, que los escritores se casaran con las hermanas o primas de sus colegas varones, como el caso de Joaquín García Icazbalceta que desposó a Filomena Pimentel, hermana de Francisco Pimentel. De ciertas poetisas que tienen en común relaciones conyugales o de parentesco con escritores. Es decir, que figuran en veladas, publicaciones y tertulias masculinas; y que ocupan también tiempos y espacios privilegiados de la vida íntima. Las poetisas que sí perseveraron en el ambiente literario del XIX, aquellas que en mayoría lograron trascender al siglo $\mathrm{XX}$, estuvieron emparentadas con literatos: eran madres, esposas, sobrinas, hijas, tías, amigas, amantes.

Josefina Pérez se casó con el famoso director de periódico y editor Vicente García Torres; Laura Méndez antes de ser esposa de Agustín Cuenca, fue madre del único hijo de Manuel Acuña; Isabel Prieto se casó con el escritor y político Pedro Landázuri, primo de Jorge Landazuri, también hombre de letras; Rosa Carreto se casó con Antonio García Tornel. Los círculos familiares también apoyaron las carreras profesionales de las escritoras. Por ejemplo, Dolores Candamo casó con José María Roa Bárcena; era cuñada de Rafael Roa Bárcena y fue abuela de María Enriqueta Camarillo Roa Bárcena. Esta última, la poetisa más famosa del XIX, se casó con el escritor, historiador y diplomático Carlos Pereyra. En el Sureste, al amparo del sabio Lorenzo Zavala, se desarrollaron sus nietas Gertrudis Tenorio Zavala y Rita Cetina Gutiérrez, quienes fundaron una empresa cultural, institución educativa que duró varias décadas: La Siempreviva. Alrededor de Fernando Calderón, el dramaturgo, sobresalieron Guadalupe Calderón, su tía y Soledad, su hija. En la línea ancestral del costumbrista José Manuel Puig Caussaranc, estaban su abuela Dolores Puig de León, Catalina Zapata Ouig y Albertina Puig, todas poetisas.

Tanto la calidad de la escritura como las relaciones de parentesco favorecieron el hecho de que las mujeres fueran publicadas por editores, entre poetas y poetisas se tendieron redes amistosas y profesionales, además de los lazos de sangre y conyugales. Hubo entonces, como ahora, amigos y admiradores de las poetisas. Los escritores y seguramente otros artistas las admiraban y fueron sus esposos, pretendientes, novios $\mathrm{y}$, ¿por qué no? sus amantes. La amistad abrió las puertas para las ediciones de obras completas y libros de versos, facilitó membresías en las asociaciones literarias, publicaciones y homenajes para ellas.

En nuestro siglo, persiste la tendencia social a formar matrimonios o familias de escritores y artistas. Sigo la respetuosa tradición de Menéndez y Pelayo -cuando se trate de literatos, no hablar de los y las vivas-, y mencionaré a Inés Arredondo que estuvo casada con Tomás Segovia; o a Amparo Dávila, que fuera secretaria de Alfonso Reyes y esposa del pintor Pedro Coronel. Cabe mencionar los matrimonios formados por Emanuel Carballo ( + en 2014) y Beatriz Espejo, el de Augusto Monterroso y Barbara Jacobs, el de Jose Emilio Pacheco (+ en 2014) y Cristina Pacheco y el de Alejandro Aura (+ en 2008) y Carmen Boullosa.

Amistades célebres 


\begin{tabular}{|c|c|}
\hline Rosa Carreto & $\begin{array}{l}\text { 1. Filomeno Mata, Manuel M. Flores } \\
\text { y muchos más que señala el editor } \\
\text { contemporáneo, L. M. Schneider, entre } \\
\text { otros. }\end{array}$ \\
\hline 2. Josefina Pérez de García Torres & $\begin{array}{l}\text { 2. Juan de Dios Peza y Juan A. Mateos, } \\
\text { suseditores }\end{array}$ \\
\hline 3. Dolores Guerrero & $\begin{array}{l}\text { 3. Luis G. Ortiz, tal vez el amado } \\
\text { (imposible. Además Guillermo Prieto, } \\
\text { Francisco Zarco, González Bocanegra, } \\
\text { Díaz Covarrubias, Marcos Arroniz, } \\
\text { según explica Peza, el biógrafo de la } \\
\text { boetisa. }\end{array}$ \\
\hline 4. Antonia Vallejo & 4. Ignacio Dávila Garibi, su editor \\
\hline 5. Esther Tapia de Castellanos & 5. Jose Lopez Portillo y Rojas, colega \\
\hline 6. Rosa Espino & 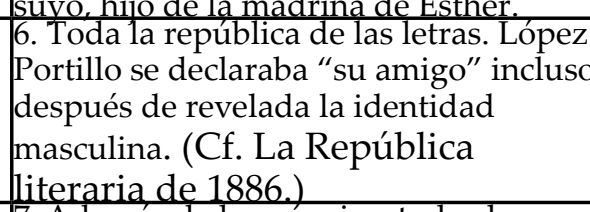 \\
\hline 7. Julia de la Peña & $\begin{array}{l}\text { 7. Además de los propios, todos los } \\
\text { admiradores de su hermana Rosario }\end{array}$ \\
\hline 8. Laureana Wright de Kleinhans & $\begin{array}{l}\text { 8amiradores de su nermanakesario } \\
\text { 8. Manuel Bolanos Cacho, su biografo }\end{array}$ \\
\hline 9. María Guadalupe Fernández & $\begin{array}{l}\text { 9. José Sebastián Segura, su ence } \\
\text { admirador. }\end{array}$ \\
\hline $\begin{array}{l}\text { 10. María Gabriela (seudónimo sin } \\
\text { identificar. Al parecer, fue una de } \\
\text { las primeras directoras de escuela } \\
\text { secundaria para señoritas). }\end{array}$ & 10.Luis G. Rubín, su editor. \\
\hline
\end{tabular}

José María Vigil, el filósofo, poeta y gran maestro, protagonista de la polémica entre el positivismo y la metafísica en México, para la educación superior, fue el mejor amigo de las poetisas. Editó para la conmemoración del IV Centenario del Descubrimiento de América una antología de la poesía femenina. En prólogos, artículos, notas biográficas y estudios críticos, los autores manifiestan abiertamente su amistad a las poetisas. Varios notables impresores y editores decimonónicos fueron asiduos amigos también. Literariamente hablando, estos agentes y promotores culturales constituyen lo que se llama "lectores privilegiados", de acuerdo con la teoría de la recepción. Como tales, incluían regularmente la escritura femenina tanto en proyectos culturales como en sus consideraciones y reflexiones sobre la literatura, en general. Además de José María Vigil y José López Portillo y Rojas -ambos conocidos como patrones o mecenas de mujeres-, hubo muchos difusores de la creatividad femenina, amigos de poetisas que consideraron que la obra femenina dignificaba a la literatura mexicana. Juan R Navarro, Niceto de Zamacois, Hilarión Frías y Soto, Juan E Barbero, Ignacio Cumplido, Juan de Dios Peza, Vicente García Torres y Cecilio Robelo entre otros.

En la actualidad, subsisten los amigos de las poetisas, aquellos críticos e investigadores que miran la obra femenina con buenos ojos, velan por sus derechos intelectuales y reeditan y difunden la poesía femenina: Emanuel Carballo, Luis Mario Schneider y Ernesto Prado Velázquez, entre otros. Mientras que Schneider y Carballo rescatan y vuelven a publicar mediante investigaciones rigurosas la poesía femenina; Carballo, historiador, denuncia el maltrato, el "ninguneo" cultural a la obra de mujeres.
Afortunadamente, las actitudes masculinas mexicanas ante la literatura femenina no se reducen a suplantar, prescribir o seducir. Gracias al respaldo de un nutrido sector de familiares y admiradores, las poetisas mexicanas se desenvolvieron y se desenvuelven, con mayor o menor fortuna, en el ambiente literario. Hasta aquí este recuento con la intención de invitar a la reescritura de la historia literaria de América Latina revisando estas dinámicas culturales.

\section{Referencias bibliográficas}

Álvarez, María Edmée, Literatura mexicana e hispanoamericana, México: Porrúa, 35ª ed, 1993. Bablot, A., “Edición Literaria”. El Federalista. México, 1872, pp.7-8. Impreso.

Balestra, B., “Palabras de Leona”. Las revoltosas. México: 2010. Impreso.

Ballesteros, L., La escritora en la sociedad latinoamericana. Cali: U. Del Valle, 1997. Impreso.

Batis, H., “Presentación”. El Renacimiento, periódico literario (1869). UNAM. México: UNAM, 1993. Impreso.

Benería, L. y Roldán, M., "Introducción y marco teórico". Las encrucijadas de clase y género México: El Colegio de México/ Fondo de Cultura Económica, 1992. Impreso.

Bourdieau, Pierre, La dominación masculina, Barcelona : Anagrama, 2000

Carner, F., "Estereotipos femeninos en el siglo XIX". Presencia y transparencia, La mujer en la Historia de México. Ed. Carmen Ramos. México: El Colegio de México, 1987. Impreso.

Conferencia Women in the Media, Facingobtscales... Changing, Mujeres en los medios, 7 y 8 de marzo de 1997, Hotel Camino Real, Ciudad de México. Convocatoria internacional de International Women's Media Foundation, anfitriona nacional María Victoria Llamas. 7-8 mar. 1997. Conferencia.

Del Palacio, C., Adictas a la Independencia, Las Mujeres de la Guerra de Independencia. México: Santillana México, 2010b. Impreso

-, Leona, Una novela sobre la gran heroína de la Independencia Leona Vicario. México: Santillana México, 2010a. Impreso.

De Olavarría y Ferrari, E., El Arte Literario en México, Málaga.1877. Impreso.

Domeq, B., Mujeres que cuentan. 7 escritoras mexicanas de su puño y letra, México: Ed. Ariadne, 1998 ,

Espejo, Beatriz, Seis niñas ahogadas en una gota de agua, México: DEMAC, ediciones especiales, 2009.

Espinoza Rugarcía, A., Talladoras de Montañas, Mujeres (en)cintas de amor. , México: Editorial Diana, 1997.Impreso.

Granillo Vázquez, L., Escribir como mujer entre hombres, historia de la poesía femenina mexicana en el siglo XIX. México: Universidad Autónoma Metropolitana, 2010. Impreso 
-, Románticas mexicanas, poesía femenina del siglo XIX, Alemania: Editorial Académica Española, 2012

Hierro, G., "La invisibilidad de la mujer en la Historia" en Metodología para los estudios de género, María Luisa González Marín, (Coordinadora), México: Instituto de Investigaciones Económica, UNAM, 1998.

Lagarde, M., Marcela, Los cautiverios de las mujeres. Madresposas, monjas, putas, presas y locas, México: Coordinación General de Estudios de Posgrado, UNAM. 2ª Edición 1993.

Llamas, M. V., (National hostess), Women in the Media Facing Obstacles, Changing, Mujeres en los Medios, Hotel Camino Real, Ciudad de México, International Women's Media Foundation, 7 y 8 de marzo de 1997.

López Hernández, M., Letras femeninas en el periodismo mexicano. Puebla: Instituto Mexiquense de cultura, 2010. Impreso.

Millán, M. C., Poesía romántica mexicana, México: Libromex editores, 1957.

Orozco, R., “A sus pies, doña Josefa”. Las revoltosas. México: Selector. Impreso.

Ramos Escandón, C., “Señoritas porfirianos: Mujer e ideología en el México progresista: 18801910". Presencia y transparencia, La mujer en la Historia de México. México:Colegio de México, 1987. Impreso.

Rojas Otarola, J., Ed. “Carta..."La Misión del escritor, ensayos mexicanos del siglo XIX. Coord. Jorge Ruedas de la Serna. México:UNAM, 1996. Impreso.

Ruiz Castañeda, M. del C., y Márquez Acevedo, S., Catálogo de seudónimos, anagramas, iniciales y otros alias usados por escritores mexicanos y extranjeros que han publicado en México. México: Universidad Nacional Autónoma de México, Instituto de Investigaciones Bibliográficas, 1985.Impreso.

-, Correcciones al catálogo de seudónimos, anagramas, iniciales y otros alias usados por escritores mexicanos y extranjeros que han publicado en México. México: Universidad Nacional Autónoma de México, Instituto de Investigaciones Bibliográficas, 1990. Impreso.

Schneider, L. M., "Cuando el General fue una Rosa”, en Homenaje a Clementina Días y de Ovando, devoción a la Universidad y la cultura. México:UNAM., 1993. Impreso.

—, Regina, México: Editorial Diana, 1996. Impreso.

Showalter, E., "Representing Ophelia: Women, Madness and the Responsabilities of Feminist Criticism". Criticism Major Statements. Ed. Charles Kaplan, William Anderson. New York: St. Martin's Press, 1991. Impreso.

Sierra, J., “Conversaciones del domingo". Obras Completas. México: UNAM, 1977. Impreso.

Sosa, F., Páginas en verso, México, 1885. Impreso.
Vigil, J.M., Obras Poéticas de la Señora Doña Isabel Prieto de Landazuri, coleccionadas y precedidas de un estudio biográfico y literario por ... primera parte, México: Composiciones líricas, Imprenta y litografía de Don Ireneo Paz, 2ª de la Independencia núm. 2, 1883.

Villalpando, J. M., Amores mexicanos. México. Planeta, 2002. Impreso.

Zamacois, N. de, “Poetas y poetisa o ellos y ellas” en El Ensayo Literario, Jalisco, México, 1852. Zendejas, A., "Ellas y la vida Lucha y conquista de los derechos femeninos". Debate Feminista. Web. 23 jun. 2013. < http://www.debatefeminista.com/articulos.php?id_articulo=1140\&id_ volumen $=37>$ 